\title{
A Reenvisioned Agricultural System in Thailand: The Growth in Human Capital Experienced by Agriculturalists After Adoption of the Sufficiency Economic Philosophy
}

\author{
A. Agard ${ }^{1}$, R. Roberts ${ }^{2}$
}

\begin{abstract}
Investments in human capital have been shown to positively influence the development of the agricultural industry in regions across the globe. After the Asian Financial Crisis of 1997, therefore, Thailand's King Bhumibol Adulyadej (The King) adopted the Sufficiency Economic Philosophy (SEP) that empowered the country through critical investments in human capital, which led to a transformation of its agricultural system. In this case study, we examined Thai agricultural leaders' reflections on the role of SEP in catalyzing such changes. Findings from this investigation emerged in the form of two investments that Thailand made in human capital through the SEP: (1) education, and (2) the establishment of the Royal Projects. Three outcomes also emerged that represent how growth was experienced in the nation's agricultural system as a result of such investments: (1) individual development, (2) economic development, and (3) societal development. As a result, this investigation's findings could help extension professionals diffuse agricultural innovations in ways that align better with the unique values of Thailand while also helping to improve the production of agricultural commodities.
\end{abstract}

\section{Keywords}

Agricultural Development, Human Capital, Sustainability, Thailand

1. Alexis C. Agard, Master Student, Louisiana State University, 131 J.C. Miller Hall, 110 LSU Union Square, Baton Rouge, LA, 70803, ; aagard1@Isu.edu, https://orcid.org/0000-0002-9261-6018

2. Richie Roberts, Assistant Professor, Louisiana State University, 131 J.C. Miller Hall, 110 LSU Union Square, Baton Rouge, LA, 70803, roberts3@lsu.edu, https://orcid.org/0000-0002-2993-4945 


\section{Introduction and Problem Statement}

After the Asian Financial Crisis of 1997, Thailand's government was forced to reevaluate its financial policy, reallocate investments, and adopt an alternative development approach (Lauridsen, 1998). And a result, King Bhumibol Adulyadej (The King) implemented the Sufficiency Economic Philosophy (SEP) throughout the country (Essen, 2010). SEP emphasizes taking the middle way or finding a balance between self-indulgence and discipline (Barua \& Tejativaddhana, 2019). As such, SEP is grounded on three pillars: (1) moderation, (2) reasonableness, and ( 3 ) and mitigating risk during decision-making (Kansuntisukmongkol, 2017). It is also believed that individuals must possess knowledge and virtue to uphold each pillar (Wibulswasdi et al., 2012). And as a result, The King argued that SEP encompassed a holistic and ethical approach toward development that could coexist with other economic systems throughout the world while also allowing the country to uphold cultural norms rooted in Buddhist traditions (Essen, 2010).

After being integrated as a core principle of Thailand's National Economic and Social Development plan in 2002, SEP has been recognized by The U.N.'s Division for Sustainable Development Goals (DSDG) as a model for sustainable development (United Nations Development Programme, 2007). In particular, evidence has demonstrated that SEP has been transformative to various aspects of Thai society including: (1) sociocultural, (2) economics and policy, and (3) education (Kansuntisukmongkol, 2017; Mongsawad, 2010; Piboolsravut, 2004; Wibulswasdi et al., 2012). However, Wibulswasdi et al. (2012) argued the most important change occurred in its agricultural system. A need emerged, therefore, to better understand how the investments to human capital through SEP led to a reenvisioned agricultural system in Thailand (Pigg et al., 2020).

\section{Theoretical and Conceptual Framework}

This study was grounded in Schultz's (1961) human capital theory. Through this lens, Schultz (1961) theorized that critical relationships existed between a society's economic growth and the investments made in its citizens' career preparation, education, and personal growth (Schultz, 1961). As a result, Schultz (1961) maintained that for a society to advance investments should be made to improve the knowledge and skills of its citizens - a concept Schultz (1961) called the development of human capital. Therefore, human capital is often linked to employability in which as an individual increases their human capital, they become more employable (Smith, 2010). A nation's investments in human capital have been shown to increase the knowledge, skills, and expertise of citizens and can lead to a more prosperous and productive economy.

It is also important to note that unlike material capital, knowledge is infinite and does not devalue (Mongsawad, 2010). In fact, human capital can be expanded and passed on from generation to generation. Therefore, through investments in human capital, societies can create sustainable solutions that yield a positive return on their investment. Despite this, 
however, Bowles and Gintis (1976) critiqued human capital theory because it placed too much responsibility on individuals to become educated, find employment, and be productive members of society. However, existing evidence has demonstrated that in many cases, employment is often influenced by factors such as socioeconomic status, ethnicity, gender, and more (Farnham, 2017; Kühn 2019).

The role of government in creating human capital and developing equitable policies for its citizens cannot be understated. In the current study, therefore, we analyzed the growth in human capital that agriculturalists experienced after the Thai monarch enacted SEP through various initiatives and policies at the national level. SEP was not a new concept, however, its adoption emerged as a result of culmination of The King's experiences during the beginning of his rule in the 1960s (Essen, 2010). For example, he discovered that many of the rural provinces were suffering from issues such as soil depletion, deforestation, and poor water quality (Essen, 2010). To combat such issues, the Thai government developed the first royal project and developmental center, Doi Angkhang (Roy et al., 2005). The Royal Project in Thailand is a concept similar to the U.S. Land-Grant system in that it provides research, extension, and teaching of agricultural sciences throughout various provinces (Roy et al., 2005). The outcomes of such investments in human capital were explicitly explored in this investigation.

\section{Purpose}

The purpose of this study was to examine leaders' reflections on the role of SEP in shaping Thailand's agricultural revitalization and growth in human capital. In summer 2019, we collected data for this investigation over four weeks. During this time, she visited local markets, royal project sites in central and northern provinces in Thailand, and other cultural activities. She also had the unique opportunity to gain access and interact with prominent agricultural leaders who were key to the successful implementation of the philosophy. Because of her role as a participant observer, she was able to gain unique knowledge and insight into SEP, which greatly shaped and influenced the design of this investigation.

\section{Methods}

Methodologically, we grounded this study using Stake's (1995) instrumental case study approach, which can provide valuable insight into bounded systems. As a result, our intent was to provide a rich description into the phenomenon that may have relevance and transferability for other similar circumstances (Stake 1995). This study was limited to the actors who had firsthand experience of SEP's implementation in Thailand. Further, we also bounded the investigation by time and location, which occurred in summer 2019 in Thailand. To achieve the purpose of this study, it was important to collect data from participants who had knowledge and insight into the impacts that SEP had on the agricultural industry. As such, we used a purposeful sampling technique (Patton, 2002) to select individuals who had a background and career involving agriculture before and after the implementation of SEP. A description of participants, using their pseudo-name, follows. 
Our first participant, Ajaan Lee, was a former professor of plant taxonomy at the Kasetsart University in Bangkok, Thailand. Ajaan Lee was selected because of his vast experience teaching and applying SEP both domestically and internationally. The second participant, Chutiya, was a Hill Tribe farmer in Northern Thailand. Chutiya's parents were farmers that participated in the original Royal Project and used SEP as a model to guide research and extension programming. The third participant, Prite, was an Extension agent for the Royal Projects in the Chiang Mai region. Meanwhile, Pui Fai, the fourth participant, was an elected representative for Chiang Mai region for the Thai parliament. It is also important to note that due to a language barrier, an interpreter was used during the interview with Ajaan Lee, creating an additional limitation for this study.

\section{Reflexivity Statement}

A critical aspect of qualitative research is to reveal the biases that influence one's perceptions and judgments (Patton, 2002). First, it is important to reveal that both authors have previous international experience in Thailand with the second author having worked extensively with Chiang Mai University prior to the collection and analysis of data. It is also important to reveal that the lead author is a first generation American, who spent her early childhood in Eastern Africa. During this time, she had the privilege of interacting in a diversity of environments and cultures. As a result, these previous experiences greatly influenced our decision to study this topic as well as how data were approached.

\section{Data Analysis and Rigor}

To uphold standards of qualitative quality and ensure trustworthiness, we built Lincoln's and Guba's (1985) four principals (1) confirmability, (2) dependability, (3) credibility), and (4) transferability into the design of this investigation. For example, we: (a) demonstrated parallelism across sources of data, (b) described our role in the study, (c) mobilized findings that were transferable to other contexts, and (d) provided context-rich descriptions.

We also collected multiple sources of data to triangulate findings. In particular, data included: (a) interviews, (b) written reflections, (c) field observations, (d) photographs, and (e) video reflections. To analyze this data, we began by breaking the data apart and grounding our analytic decisions in Saldaña's (2015) recommendations. As such, we used the following coding techniques to facilitate the constant comparative method on each source of data: (a) open, (b) axial, and (c) selective (Saldaña, 2015). Open coding is the process by which researchers generate as many codes as possible through an inductive thinking process. Open coding was accomplished by employing Saldaña's (2015) in vivo coding approach by which we used participants' words to capture the essence and essential elements of the data corpus. After identifying open codes, we started organizing and linking relationships among the open codes through the axial coding approach (Saldaña, 2015). Through our analysis of the characteristics and dimensions of each code, we were able to reduce the data to categories (Saldaña, 2015). After developing categories, we reduced the data further using selective coding by which we used Shultz's (1961) human capital theory to make sense of the categories. This process helped emerge the study's findings (Saldaña, 2015). 


\section{Findings}

The findings for this study emerged in the form of two investments that The King made in human capital through the SEP: (1) education, and (2) the establishment of the Royal Projects. Three outcomes also emerged that represent the growth experienced in Thailand's agricultural system as a result of such investments: (1) individual development, (2) economic development, and (3) societal development. In the presentation of findings, we offer a description of how the adoption of the SEP by The King and subsequent investments in human capital led to a reenvisioned agricultural system in Thailand. To promote the transferability of this investigation's findings, we integrated such into a visual representation at the report's conclusion and offer implications for future research, theory-building, and practice. conclusion and offer implications for future research, theory-building, and practice.

\section{Investment \#1: Education}

During fieldwork, we conducted extensive observations and interactions with Ajaan Lee. As a result, she was able to gain insight in the types of investments in human capital (Shultz, 1961) made in agriculture as a result of the adoption of the SEP. When asked about his historical perspective on such investments, Ajaan Lee revealed that The King was " [was] interest[ed] in agriculture so he traveled to many remote areas where even I cannot walk... so he knew a lot of the problems..." regarding agriculture. Through The King's observations of agrarian life in Thailand, therefore, he came to understand the power of knowledge, the value of agriculture, and how to bring change to his country through education. Prite explained:

... [The King] also knew a lot of the problems on the drug trafficking so he started the project called The King's Royal Projects to tackle problems [regarding] drug trafficking...[and] poverty. [So] he used agriculture as the base for tackling the entire problems [of Thailand]. He devoted [his life] to this until he died...

Although poverty and drug trafficking were rampant in these regions, previously no attempts had been made to resolve these issues until The King intervened in 1969. In response, he created several educational initiatives through SEP to combat the poverty, deforestation, and the trafficking of opium by the Hill Tribe villagers. Pui Fai explained these educational initiatives lead to the development of the original Royal Project, Doi Angkhan, located in the mountains of Chiang Mai. Chutiya also revealed that her "parents were the [original] farmers of the Royal project foundation." And, as a child, she witnessed a great transformation to Thailand's agricultural sector when The King eradicated the growing of opium and incentivized food crops such as rice and vegetables. Chutiya also described how such initiatives were key to her education: "after grade six [I] transitioned into the royal project where [I] was taught organic vegetables growing techniques" which she continues to expand today. She continued: "before the inception of the Royal Project there weren't schools around here but since the project started they have schools here and a lot of people who work with the Royal Project are able to send their kids to the schools." This investment in human capital expanded beyond Thailand's boarders as well. For instance, Prite revealed through the SEP, some agricultural education initiatives were "organized by the military [so that] ... people from Myanmar [could] learn 
growing techniques." Ajaan also added that "...in some countries like Kenya, Uganda, and Rwanda we sent people [from Thailand] to expand the idea of [SEP] and the Princess has some stations in Myanmar and Laos to try to help [educate] them" as well.

\section{Investment \#2: The Establishment of Royal Projects}

The King also invested in human capital through the establishment of the Royal Study Centers. During fieldwork, we observed the Royal Project and Study Centers on a trip to Khao Hin Sorn Royal Development Study Center. She also noted that the Royal Projects appeared to be modeled after the U.S. Land-Grant Institution system. For example, the Royal Development Centers work in cooperation with universities and government agencies to function as agricultural research stations. The knowledge gained from this research is then passed on to agriculturalist through Extension agents (see Figure 1). Often, farmers and others engaged in the agricultural industry are encouraged to visit the development centers to enhance their knowledge on sustainable agriculture practices. Khao Hin Sorn is dedicated to conducting research on land development and environmental conservation practices as well as transferring such knowledge to appropriate stakeholders.

\section{Figure 1}

\section{Extension Agents in Thailand Providing Education}

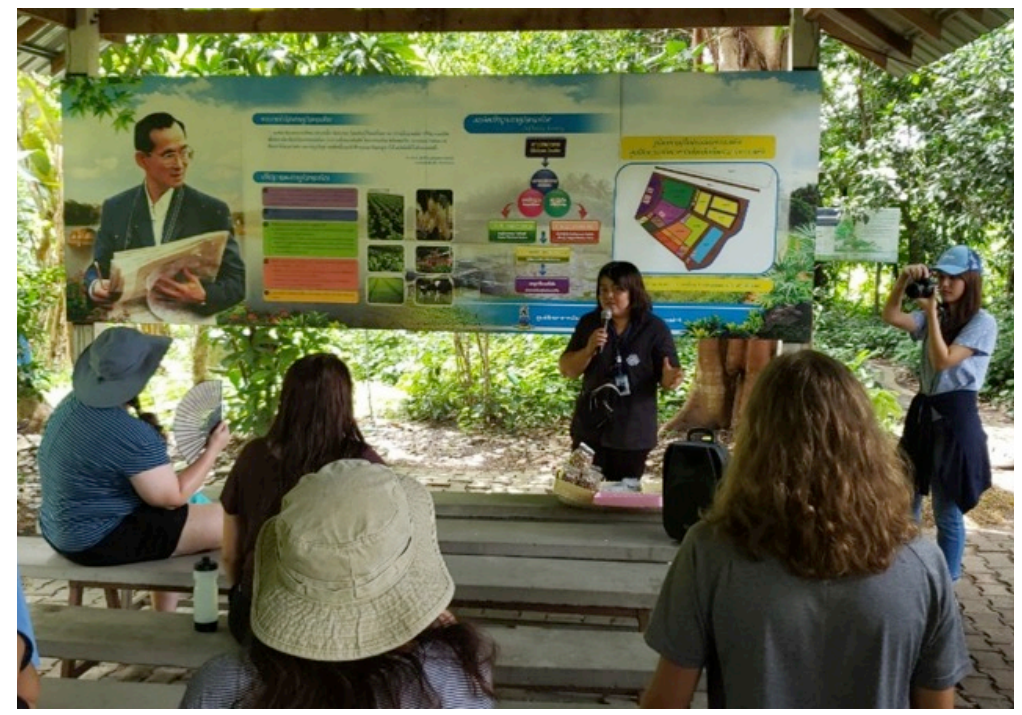

At Khao Hin Sorn, we noted how green, luscious, and vibrant the land was in the region. However, during our visit to Doi Angkhan, she collected historical artifacts that described this was mainly due to the sustainable development policies implemented by The King through SEP. We were also able to view images of the land before The King had intervened. The land was dry, the soil depleted, and there was little to no trees left due to the slash and burn methods used by the farmers (see Figure 2). 


\section{Figure 2}

Archival Images Depicting Northern Thailand in the 1960s Before the Adoption of SEP

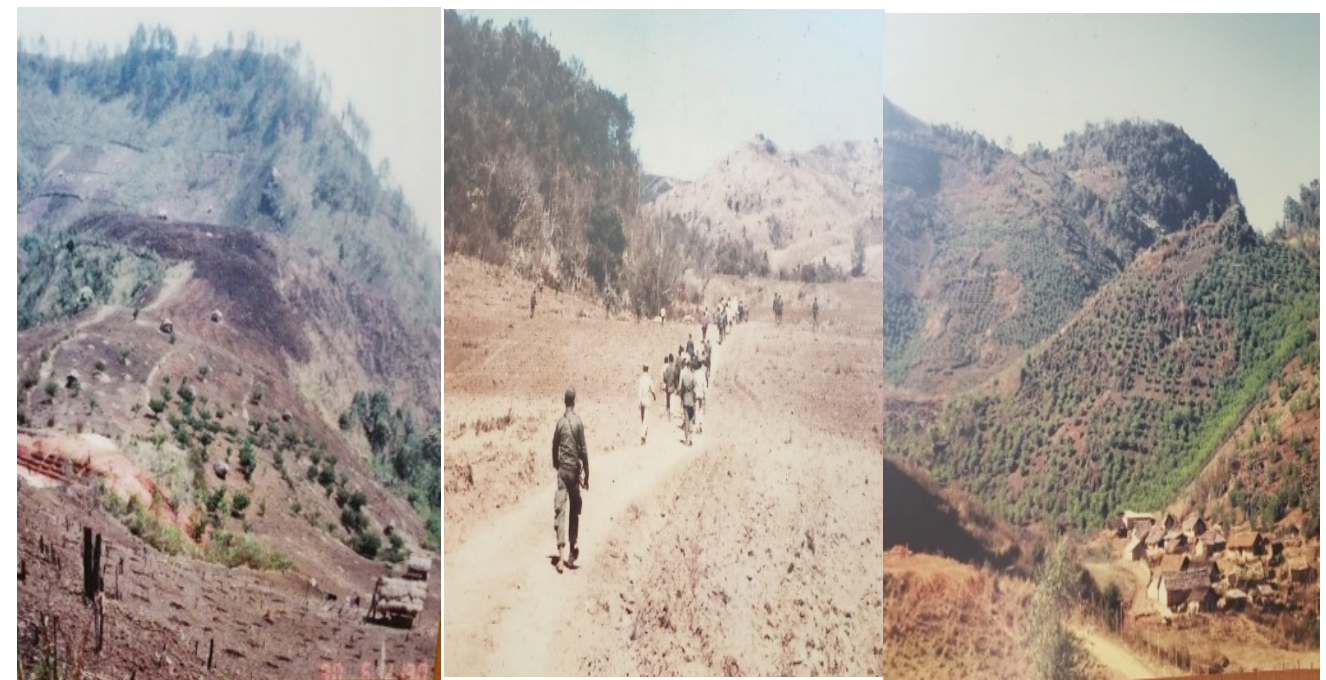

Note. Images collected from the Doi Angkhan Development Study Center.

After 50 years, The King's efforts helped transform the land in Northern Thailand (see Figure 3). However, Pui Fai argued that this transformation would not be possible without The King's investments in the Hill Tribe people. For example, members of the Hill Tribe were educated and trained to operate the Royal Projects. Chutiya maintained "most people are happy to produce and send produce to the Royal Project." Now, what was once dirt and dust has been completely revitalized into a green, luscious farmland.

\section{Figure 3}

Images of Doi Angkhan captured in June 2019, Depicting the Transformation of Northern Thailand as a Result of Investments to Human Capital Made through the SEP
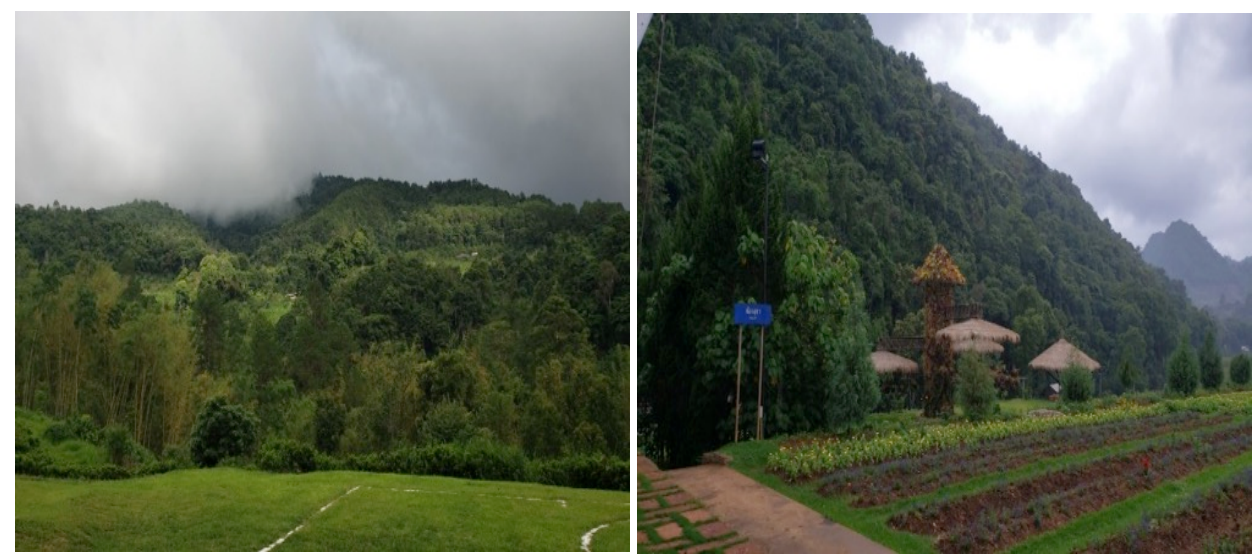

Note. Images captured during fieldwork in 2019. 


\section{Outcome \#1: Individual Development}

The investments in human capital in the form of education and the establishment of the Royal Projects resulted in the three key outcomes. The first outcome that emerged from our analysis was the fostering of individual development. As an illustration, instead of criminalizing the Thai people for growing opium, The King gave them an opportunity to create a sustainable livelihood through agriculture. In particular, he developed small projects, which Prite explained allowed each family to obtain ". . . one hectare of land to grow their food." He maintained, "...the money doesn't make [them] rich, but at least [they] are able to survive and take care of themselves...." By providing land, therefore, the Thai people were able to enhance their individual development by growing food, which reduced poverty. Ajaan Lee explained:

... because Thailand is diverse in plants and animals that the people can use, if they have the knowledge they can plant it all together in a small area which is suitable for the situation for Thai famil[ies]...

Through the implementation of the SEP, lower income individuals acquired the knowledge to be self-reliant, live in moderation, and be prepared for life's unexpected challenges. Or as Chutiya suggested: "SEP is useful for everyone, you can adapt it to your own situation. You should be content with what you have and not be greedy."

\section{Outcome \#2: Economic Development}

Through our interactions with officials at the Royal Projects, we observed that SEP has contributed to the economic development of Thailand through sustainable agriculture and ecotourism. Further, it has also enhanced the livelihoods of Thai people through cooperatives as well as rehabilitated the environment in many regions. Further, the SEP also promoted the development of community economic wealth. Ajaan Lee described how economic development was fostered as a result of SEP in the following passage: "If you have some surplus production you can sell it to the local market." As a result, the Hill Tribe people were able to grow their local markets, which helped to expand resources for their villages. Throughout much of Thailand, cooperatives are encouraged to help strengthen communities and bring economic prosperity. During one of our excursions, we visited Talaad Thai Market, which is Thailand's largest wholesale agriculture product market. During this experience, we noted the critical role of cooperatives and observed how they aided in the country's economic development (see Figure 4). 


\section{Figure 4}

Images of Talaad Thai Market
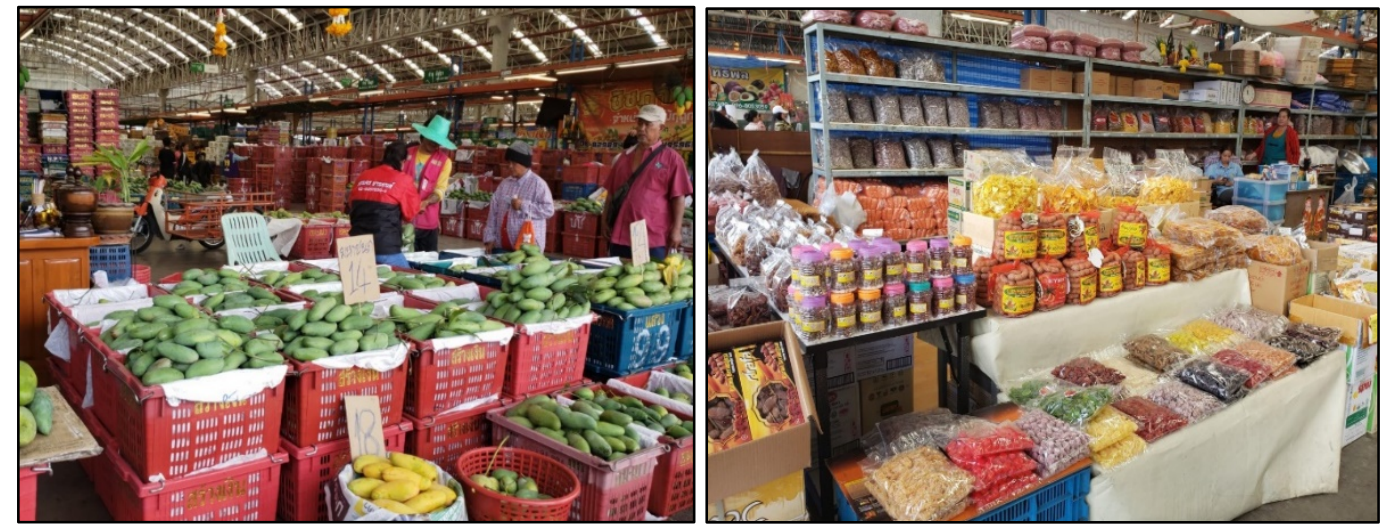

\section{Outcome \#3: Societal Development}

In our fieldnotes, we noted that Thailand appeared "peaceful" and the "people seemed to be less stressed and healthier" in comparison to more developed regions of the world. Through our analysis of the data, we interpreted such aspects of society to be largely influenced by the adoption of SEP. To this point, Pui Fai explained that because of SEP, many Thai people have adopted safer agricultural practices and adopted the perspective they should avoid the use of chemicals to protect "... the health of the consumer, the health of the farmer, and [the rest of] the food chain."

Although the adoption of SEP greatly contributed to Thai agricultural development, it also deemphasized greed. For example, Prite explained that SEP promoted prudence by discouraging the overabundance of resources, which shifted the perspective that individuals should strive to "... get a lot of money." In recent years, however, Ajaan Lee described that changes were occurring by which "...the present government is more stressed on the industrial sector...they don't pay much attention to the agriculture sector." As a consequence, Pui Fai cautioned that "...the land area is the same, you cannot expand [it] and you have less and less resource[s]. If you don't have a good agriculturist this [will] be the problem for the whole world, not only for Thailand..." By practicing SEP, therefore, Thai agriculturist learned how to live a balanced life with the consideration of others by monitoring how and what they consume. The adoption of the SEP and key investments in human capital, therefore, led to a reenvisioned agricultural system in Thailand.

\section{Conclusions, Discussion, and Recommendations}

In this study, we demonstrated how Thailand's adoption of SEP led to the two key investments in human capital: (1) education, and (2) the establishment of Royal Projects. Because such investments, three outcomes for Thailand's agricultural industry also emerged: (a) individual 
development, (b) economic development, and (c) societal development. Therefore, we conclude that Thailand's adoption of SEP and subsequent investments in human capital led to a transformation in the agricultural industry (see Figure 6) (Essen, 2010).

\section{Figure 6}

A Visual Representation of How Investments in Human Capital through SEP Led to a Reenvisioned Agricultural System in Thailand

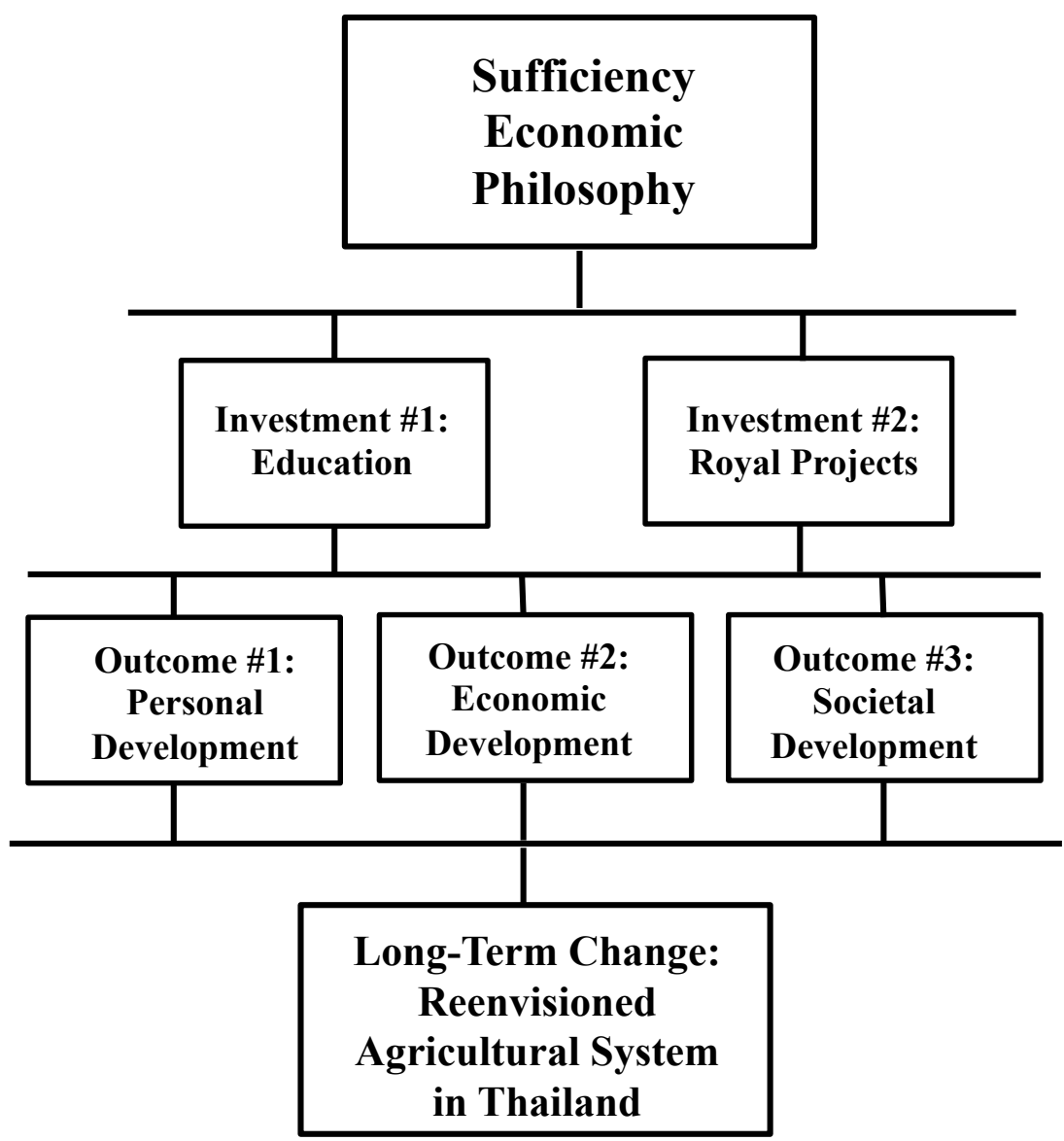

The first outcome, individual development, emphasized the development of the Thai people through the Royal Projects. For example, participants reported individuals were able to increase their knowledge and skills through improved educational systems as well as opportunities to develop professionally through experiences at Royal Project sites. We conclude that such investments appeared to decrease the Thai people's external dependency and enabled them to be self-reliant while also improving their overall well-being. Findings from this study, therefore, provided new insights into the importance that personal development made in allowing the Thai people to acquire the resources needed to be self-reliant. The second outcome, economic development, demonstrated the role of policies in supporting the growth of local cooperatives and the tourism industry. As an illustration, the policies enacted under SEP by The King helped create one of the largest markets in Thailand, Taalad Thai Market, which contributed greatly to the economic growth in the region. This finding aligns with those reported by Mongsawad 
(2010) regarding the importance of the governmental policies on influencing the development of community enterprises and local markets. Societal development, the final outcome, referred to how SEP encouraged a culture of balance and sustainability in Thai agriculture. Such a change promoted health as well as unity among the Thai people. Previous literature on the role of societal development suggested that self-evaluation and self-accountability were critical cultural implications to the adoption of SEP.

Future research should explore the ways in which various regions and cultural groups (Roberts \& Edwards, 2017) in Thailand interpret and operationalize SEP in diverse ways. Such an understanding could also help Extension agents to introduce new agricultural techniques and principles by tailoring the messaging and educational programming in ways that align with the unique values of each region while also helping to improve the production of agricultural commodities throughout the country. Further, additional work is also needed to explore the dimensions of the outcomes - individual, economic, and societal - identified in the investigation. For example, future research should seek to explore how each outcome influences the social dimensions of Extension work in Thailand and examine which outcome has yielded the most transformative benefits for agriculture since the Asian Financial Crisis of 1997 (Lauridsen, 1998).

This study also suggested important insights into how SEP and human capital theory are intimately connected and bolster each other when considered in tandem. As such, we recommend that future theory-building efforts be dedicated to describing the interrelations between the two concepts. Finally, this investigation also opened up critical implications for future practice. For instance, individuals who seek to create change in Thailand's agricultural system should become well versed in the principles of SEP and be able to use the language of the philosophy when communicating with Extension agents and other locals. In recent decades, SEP, and its associated terminology, has become central to the everyday life, especially in the northern and central regions of Thailand where the production of agricultural commodities is most prominent. Consequently, we recommend that the principles of SEP be more significantly integrated into the schooling and professional development of agricultural professionals throughout the region.

\section{References}

Barua, P., \& Tejativaddhana, P. (2019). Impact of application of Sufficiency Economy Philosophy on the well-being of Thai population: A systematic review and meta-analysis of relevant studies. Journal of Population and Social Studies, 27(3), 195-219. https://doi.org/10.25133/JPSSv27n3.0013

Bowles, S., \& Gintis, H. (1976). Schooling in capitalist America. Basic. 
Essen, J. (2010). Sufficiency economy and santi asoke: Buddhist economic ethics for a just and sustainable world. Journal of Buddhist Ethics, 17, 71-99. http://enlight.lib.ntu.edu.tw/FULLTEXT/JR-MAG/mag386252.pdf

Farnham, D. (2017). The changing faces of employment relations: Global, comparative and theoretical perspectives. Palgrave Macmillan Education.

Kansuntisukmongkol, K. (2017). Philosophy of sufficiency economy for community-based adaptation to climate change: Lessons learned from Thai case studies. Kasetsart Journal of Social Sciences, 38(1), 56-61. 1 https://doi.org/10.1016/j.kjss.2016.03.002

Kühn, S. (2019). Global employment and social trends. World Employment and Social Outlook, 2019(1), 5-24. https://doi.org/10.1002/wow3.150

Lauridsen, L. S. (1998). The financial crisis in Thailand: Causes, conduct and consequences? World Development, 26(8), 1575-1591. https://doi.org/10.1016/s0305-750x(98)00069-2

Lincoln, Y. S., \& Guba, E. G. (1985). Naturalistic inquiry. Sage.

Mongsawad, P. (2010). The philosophy of the sufficiency economy: A contribution to the theory of development. Asia-Pacific Development Journal, 17(1), 123-143. https://doi.org/10.18356/02bd5fb3-en

Piboolsravut, P. (2004). Sufficiency economy. Asian Economic Bulletin, 21(1), 127-134. https://doi.org/10.1355/ae21-1h

Pigg, J., Richardson, M. A., Roberts, R., \& Stair, K. S. (2020). Awakening transformative learning: A comparison of the dissonance experienced by agriculture majors during study abroad courses to Costa Rica and Thailand. Journal of International Agricultural and Extension Education, 27(3), 132-147. https://doi.org/10.5191/jiaee.2020.273132

Roberts, R., \& Edwards, M. C. (2017). Challenges to sustaining university-community partnerships in war-torn, northern Uganda: Investigating resistance, negative stereotyping, and gender bias in agricultural students' attachments. Journal of International Agricultural and Extension Education, 24(2), 4-21. https://doi.org/ 10.5191/jiaee.2017.24201

Roy, J. D., Lake, J. N., Gray, L. C., \& Frost, T. W. (2005). Educational and social development in Doi Ang Khang: A comparative study of the Khob Dong and Nor Lae Villages. https://digitalcommons.wpi.edu/iqp-all/2474

Saldaña, J. (2015). The coding manual for qualitative researcher (3rd ed.). Sage.

Patton, M. (2002). Qualitative research and evaluation methods (3rd ed.). Sage. 
Schultz, T. (1961). Investments in human capital. The American Economic Review, 51(1), 1-17. https://core.ac.uk/reader/6590790

Smith, E. (2010). Sector-specific human capital and the distribution of earnings. Journal of Human Capital, 4(1), 35-61. https://doi.org/10.1086/655467

Stake, R. E. (1995). The art of case study research. Sage.

United Nations Development Programme. (2007). Thailand human development report, 2007: Sufficiency economy and human development. http://hdr.undp.org/sites/default/files/thailand 2007 en.pdf

Wibulswasdi, C., Piboolsravut, P., \& Pootrakool, K. (2012). Sufficiency economy philosophy and development. Sufficiency Economy Research Project, Bureau of the Crown Property.

(C) 2020 by authors. This article is an open access article distributed under the terms and conditions of the Creative Commons Attribution license (http://creativecommons.org/licenses/by/4.0/). 